\title{
POLÍTICA EXTERNA BRASILEIRA, COOPERAÇÃO SUL-SUL E EDUCAÇÃO SUPERIOR: O CASO DO PROGRAMA ESTUDANTE-CONVÊNIO DE GRADUAÇÃO
}

\author{
Fernanda Geremias LeaL ${ }^{1}$ \\ Mário César Barreto Moraes ${ }^{1}$
}

\begin{abstract}
RESUMO: A Educação Superior é um dos principais setores da Cooperaçáo Internacional para o desenvolvimento no campo da Política Externa Brasileira (PEB). Uma importante iniciativa do setor é o incentivo para estudantes de países em desenvolvimento realizarem seus estudos em universidades brasileiras, feito pelo Programa Estudante-Convênio de Graduação (PEC-G), regulamentado em 1965. Este artigo caracteriza o PEC-G na ótica da Cooperação Sul-Sul (CSS) brasileira. Assim, estabelece um diálogo entre as peculiaridades da sua regulamentação, suas características atuais, a PEB e a CSS. O decreto que instituiu o PEC-G se evidenciou como política de controle, pautada na segurança nacional. Apesar de sua ascensão em um sentido cooperativo, suas condicionalidades o afastam do discurso oficial empregado para a CSS.
\end{abstract}

Palavras-chave: Política externa brasileira. Cooperação Sul-Sul. Educação Superior.

\section{BRAZILIAN FOREIGN POLICY, SOUTH-SOUTH CoOperation AND Higher EduCATION}

\begin{abstract}
Higher Education refers to one of the main sectors of the International Cooperation for Development in the field of the Brazilian Foreign Policy (PEB). An important initiative of this sector, aimed at the education of students from developing countries in Brazilian universities, is the Program Student-Management Agreement (PEC-G), regulated in 1965. This article characterizes the PEC-G from the viewpoint of the Brazilian South-South Cooperation (CSS). Thus, a dialogue between the particularities of its regulation, its current characteristics, the BFP and the SSC is established. The law underlying PEC-G was proven a control policy focused on national security. Despite its rise from a cooperative sense, its conditions stands apart from the official speech used for SSC.
\end{abstract}

Keywords: Brazilian foreign policy. South-south cooperation. Higher education.

\footnotetext{
${ }^{1}$ Universidade do Estado de Santa Catarina, Programa de Pós-Graduação em Administração Florianópolis (SC), Brasil. E-mails: fernanda.leal@ufsc.br, mcbmstrategos@gmail.com DOI: 10.1590/ES0101-73302018174127
} 


\title{
POLITIQUe ÉTRANGÈRe BRÉSILIENNE, COOPÉRATION SUD-SUD ET ENSEIGNEMENT SUPÉRIEUR
}

\begin{abstract}
RÉSUMÉ: L'enseignement supérieur se réfere à l'un des principaux secteurs de la coopération internationale pour le développement dans le domaine de la Politique Étrangère Brésilienne (PEB). Une initiative importante dans le secteur, visant à la formation des étudiants des pays en développement dans les universités brésiliennes, est le Programme Étudiant-Entente de Gestion (PEC-G), réglementé en 1965. Cet article présente le PEC-G sur la perspective de la Coopération Sud-Sud (CSS) brésilienne. On établit un dialogue entre les particularités de sa réglementation, ses caractéristiques actuelles, la PEB et la CSS. Il s'est avéré que le décret instituant le PEC-G était une politique de contrôle orientée vers la sécurité nationale. Bien qu’il soit apparu sur les bases d'un sens de coopération, leurs conditionnalités divergent du discours officiel employé pour la CSS.
\end{abstract}

Mots-clés: Politique étrangère brésilienne. Coopération sud-sud. L'enseignement supérieur.

\section{Introdução}

A

Cooperação Internacional para o Desenvolvimento (CID) adquiriu centralidade no debate sobre a Política Externa Brasileira (PEB) nos anos 2000, quando o País ampliou sua capacidade de oferecer projetos de cooperação (SOUZA, 2014; MILANI et al., 2015; 2016). Conceitualmente, a cooperação horizontal, ou a Cooperação Sul-Sul (CSS), que implica antes uma relação de benefícios mútuos entre os parceiros do que um vínculo pautado no assistencialismo; tornou-se, assim, expressiva categoria instrumental da PEB (VALENÇA; CARVALHO, 2014).

No entanto, sendo o Brasil um Estado com persistentes desafios internos relacionados à desigualdade social e ao seu próprio desenvolvimento, sua condição protagonista na CSS acompanhou uma crescente necessidade de justificação política interna em relação às despesas destinadas a esse fim (SOUZA, 2014). Esse cenário revela que a política externa é, com efeito, política pública, e, nesses termos, promove articulações e arranjos institucionais-burocráticos internos, ao mesmo tempo em que suscita demandas e conflitos de grupos domésticos distintos (SALOMÓN; PINHEIRO, 2013).

Contemporaneamente, um dos setores mais significativos de atuação do Brasil no que se refere ao desenvolvimento de países de baixa e média rendas é a Educação. Destacam-se projetos relativos à Educação Superior, cuja maior parte 
dos gastos se destina à concessão de bolsas a estudantes dos Países Africanos de Língua Oficial Portuguesa (Palop), no caso da graduação, e de países latino-americanos, no caso da pós-graduação (MILANI et al., 2015;2016).

O mais antigo programa governamental brasileiro de cooperação internacional na Educação Superior é o Programa de Estudantes-Convênio de Graduação (PEC-G), regulamentado pelo Governo Federal em 1965 (BRASIL, 2016d). Os estudantes de países em desenvolvimento com os quais o Brasil mantém acordos de cooperação realizam seus estudos em universidades brasileiras, na expectativa condicionante de retorno à nação de origem após a obtenção do título. Assim, espera-se que a cooperação internacional brasileira cause impacto positivo nas sociedades dos países parceiros (MILANI et al., 2015).

Apesar da tradicional existência do programa, são limitados os estudos que se preocuparam em relacioná-lo ao contexto histórico e paradigmático da PEB ou, ainda, em analisá-lo sob as lentes da CSS. Este artigo busca suprir essa lacuna e, para tanto, estabelece como objetivo caracterizar o PEC-G na ótica da CSS brasileira, tendo como referência o questionamento "em que medida as estratégias brasileiras de Cooperação Sul-Sul se constituem em uma real alternativa ao desenvolvimento?" (MILANI et al., 2016, p. 17). Trata-se de uma pesquisa qualitativa, bibliográfica, documental e analítica, que coteja bases teóricas sobre PEB e CSS com bases documentais inerentes a práxis do programa.

\section{Ajuda internacional para o desenvolvimento e Cooperação Sul-Sul}

A ajuda internacional Norte-Sul ${ }^{1}$ legitimou-se com a suposição de que a transferência de recursos financeiros, de bens ou de serviços das potências industrializadas viabiliza o desenvolvimento econômico dos Estados receptores (MORGENTHAU, 1962). Inerente a essa premissa está a filosofia de que o processo de desenvolvimento é livre de conflitos e envolve, essencialmente, mobilização de recursos e definição das estratégias e soluções mais adequadas para tal fim (DEGNBOL-MARTINUSSEM; ENGBERG-PEDERSON, 2003).

Foi em um contexto marcado pela Guerra Fria e pelo crescimento econômico acelerado do ocidente que a CID ganhou espaço (LANCASTER, 2007; LEITE, 2012). Segundo Souza (2014, p. 14), "a partir dos anos 1960, os países membros do Comitê de Assistência ao Desenvolvimento [...] passaram a ser conhecidos como doadores tradicionais, conquanto os países do chamado terceiro mundo, ele mesmo um grupamento altamente heterogêneo, eram identificados como recipiendários".

A justificação teórica da ajuda Norte-Sul tem sido amplamente discutida desde então, sem estabelecimento de consenso (MAWDSLEY, 2012). As motivaçōes para doar e receber variam significativamente, sendo que as puramente 
morais e humanitárias - únicas não políticas, segundo Morgenthau (1962) - são raras. As relações de poder implícitas nos acordos criam expectativas e constrangimentos nos atores envolvidos, intensificados pela soberania do doador no estabelecimento da agenda e das condiçóes da assistência (LANCASTER, 2007; DEGNBOL-MARTINUSSEM; ENGBERG-PEDERSON, 2003).

O cenário de descontentamento com as assimetrias evidenciadas na arena internacional, de questionamento sobre a efetividade do modelo ocidental de desenvolvimento e de críticas ao modelo assistencialista induziu a CSS a adquirir importância. Seus antecedentes históricos são o Movimento dos Não-alinhados, o Grupo dos 77, os primeiros arranjos regionais e subregionais de integração dos anos 1960, a Nova Ordem Econômica Internacional e a Organizaçáo dos Países Exportadores de Petróleo (OGWU, 1982). Nos anos 2000, a recuperação econômica das potências emergentes e sua insatisfação com os impactos dos programas de emergência e ajuste estrutural contribuiram para que elas formassem coalizóes e buscassem novas parcerias.

A reciprocidade e a horizontalidade são premissas inerentes à construção do conceito de CSS, que se lança como relaçáo de benefícios mútuos, pautada na ausência de condicionalidades e distante de um vínculo assistencialista. É oportuno considerar, entretanto, que essa modalidade de cooperação internacional apresenta diferentes significados (STEINER-KHAMSI, 2009; MAWDSLEY, 2012). Leite (2012) observa que o único denominador comum nas definiçôes é sua referência às dinâmicas no âmbito de países em desenvolvimento. Ogwu (1982) sustenta que uma interpretação romântica compreende a CSS como meio para que as naçóes excluídas se oponham à capacidade dos países ricos de penetrar em suas economias.

A despeito do sentimento de que a CSS constitui um potencial para que as relaçóes internacionais ocorram em condiçôes de menor desigualdade (CHISHOLM, 2009), é pouco realista pensar que ela seja despolitizada. Em alguns casos, as assimetrias evidenciadas na ajuda tradicional se reproduzem nas relações do Sul. O próprio processo de desenvolvimento não é livre de conflitos e implica desafios relativos às especificidades, aos aparatos burocráticos e às políticas de cada Estado (LANCASTER, 2007).

Questiona-se, portanto, se a CSS apresenta condiçóes de libertar-se das dinâmicas de poder e de interesse ou, ainda, se representa uma nova ordem de dependência (OGWU, 1982). Segundo Leite (2012), a teoria social demonstra que a cooperação é um fenômeno complexo, que engloba recompensas materiais ou imateriais; diretas ou indiretas. O quadro também suscita debates sobre os desafios enfrentados pelos países participantes, como a dicotomia de ser doador e vivenciar problemas estruturais internos. Assim, da mesma forma que a suposiçáo de que a ajuda internacional constitui-se como instrumento de política externa é controversa (MORGENTHAU, 1962), também são controversas as hipóteses relativas à CSS, que se intensificam pela lacuna de estudos empíricos a seu respeito. 


\section{Antecedentes históricos e objetivos da Cooperação Sul-Sul na política externa brasileira}

A política externa do Brasil foi historicamente construída em torno de um empreendimento majoritário: o desenvolvimento do país por meio de autonomia e de um papel significativo no sistema internacional - ainda que, em certos momentos, tal empreendimento tenha se traduzido em um alinhamento, automático ou pragmático, a determinada potência. Houve predominância de uma visão realista do sistema internacional, no qual os Estados operam em busca de ganhos relativos ou absolutos, a partir de uma conjugação dinâmica dos interesses e das percepçóes de seus representantes (SOARES DE LIMA, 1994; FLEMES; SARAIVA, 2014; PINHEIRO, 2000; 2004; VIGEVANI; CEPALUNI, 2007).

Pinheiro (2004) argumenta que dois paradigmas sustentaram alternadamente a PEB entre 1889 e 1990: o americanismo, caracterizado pela busca de um alinhamento com os Estados Unidos como forma de elevar os recursos financeiros e tecnológicos de poder; e o globalismo, voltado à diversificação das relaçóes exteriores como condiçã̃o do aumento de sua barganha no cenário internacional.

A origem da CSS na PEB remete aos períodos de enfraquecimento da crença de que o Brasil usufruía de condiçáo de aliado especial junto aos Estados Unidos. Não obstante a intensificaçáo qualitativa e quantitativa da participaçáo brasileira na CSS a partir dos anos 2000, pelo menos dois momentos anteriores apresentam indícios de multilateralidade na inserção internacional do país.

O primeiro ocorreu entre o fim dos anos 1950 e o início dos anos 1960, com uma projeção desenvolvimentista. A percepção foi reforçada pelas teses do Instituto Superior de Estudos Brasileiros (Iseb) e da Comissão Econômica para a América Latina (Cepal) e sistematizada pela Política Externa Independente (PEI), nos governos de Jânio Quadros e João Goulart (VISENTINI, 1999; PINHEIRO, 2000; 2004). $\mathrm{O}$ segundo ocorreu no regime militar, com o pragmatismo responsável de Geisel. Para arcar com a crescente dívida externa e equilibrar o balanço de pagamentos, o modelo desenvolvimentista incorporou uma política de promoçáo de exportaçóes, o que somente seria possível com a diversificação de parcerias. Os pressupostos do globalismo se mantiveram no governo Figueiredo (PINHEIRO, 2000).

O esgotamento da capacidade explicativa do americanismo e do globalismo, fortalecido pela crise do modelo nacional-desenvolvimentista e pelo aumento da vulnerabilidade externa na segunda metade dos anos 1980 (SOARES DE LIMA, 1994; VISENTINI, 1999; PINHEIRO, 2000; 2004), induziu ao surgimento de uma terceira possibilidade paradigmática nos anos 1990: o institucionalismo pragmático, caracterizado pelo fortalecimento das instituiçóes multilaterais e pela articulação com o meio internacional como forma de "acesso ao desenvolvimento e à autonomia de ação" (PINHEIRO, 2000, p. 326). 
Simbolicamente, o discurso do Governo Lula enfatizou a necessidade de mudanças em relação aos mandatos de Fernando Henrique Cardoso. No entanto, para Vigevani e Cepaluni (2007), a transição não implicou em ruptura paradigmática: a PEB seguiu como instrumento de desenvolvimento econômico e de preservaçáo e ampliação da autonomia do país, ideia que, segundo Soares de Lima (1994), é inerente às relaçōes internacionais de potências médias. As preferências, contudo, eram divergentes. Enquanto a política externa de Cardoso teve como estratégia a busca da autonomia pela participação, a de Lula da Silva pautou-se na autonomia pela diversificação (VIGEVANI; CEPALUNI, 2007). As principais diferenças concentraram-se, portanto, nas distintas interpretações e ideologias de seus formuladores quanto às possibilidades e aos constrangimentos da ordem internacional.

Segundo Engstrom (2012), a política externa de Lula da Silva foi conduzida com base em quatro principais linhas: a atuação do Brasil como advogado para reformas gerais de governança, sua projeçáo de poder, seu papel de liderança regional e seus esforços para fomentar as relaçóes Sul-Sul. Vigevani e Cepaluni (2007, p. 292) complementam que a "retomada e o estreitamento das relaçóes com os países africanos" constituiu-se como uma das ênfases prioritárias da PEB. Sob o discurso presidencial de que o Brasil "tem um compromisso moral e ético com o continente africano"2, o país, ao lado da China e da Índia, tornou-se um dos mais importantes atores na política internacional da África, reforçando o papel significativo do continente na projeção brasileira no mundo.

Além de objetivos comerciais imediatos, a presença brasileira no continente africano, o ativismo brasileiro nas arenas multilaterais e a construção de coalizóes buscavam contrabalancear as relaçóes Norte-Sul. Enfatizou-se "a adesão do país aos princípios e às normas internacionais por meio de alianças Sul-Sul, inclusive regionais, e de acordos com parceiros não tradicionais" (VIGEVANI; CEPALUNI, 2007, p. 283). As narrativas oficiais relativas à CSS reforçaram premissas como "solidariedade, horizontalidade, não ingerência, respeito à soberania estatal, não uso de condicionalidades políticas relacionadas a direitos humanos e democracia liberal; compartilhamento de experiências e práticas de políticas públicas etc." (MILANI et al., 2016, p. 29). A defesa de temas náo relacionados a interesses imediatos também foi realçada, em parte como estratégia de soft power ${ }^{3}$ (VALENÇA; CARVALHO, 2014; FLEMES; SARAIVA, 2014).

Milani et al. (2016), a partir de dados do Instituto de Pesquisa Econômica Aplicada (Ipea) e da Agência Brasileira de Cooperação (ABC), apresentam um panorama da atuaçáo do Brasil como doador na cooperação para o desenvolvimento. Os principais destinos foram países latino-americanos $(68,1 \%)$ e africanos $(22,6 \%)$. No caso destes, os mais recorrentes foram os Palop, com 76,5\% dos gastos. Um dos principais setores de atuação do Brasil na CSS é a Educação. 
O mais tradicional programa governamental de cooperação internacional no campo da educação superior é o PEC-G, regulamentado em 1965. Os estudantes de países em desenvolvimento realizam seus estudos em universidades brasileiras, na expectativa condicionante de retorno à nação de origem. Assim, espera-se que a cooperaçáo internacional brasileira cause impacto positivo nas sociedades dos países parceiros, ainda que tais resultados sejam altamente subjetivos (MILANI et al., 2015).

\section{Programa Estudante-Convênio de Graduação (PEC-G)}

A regulamentação do PEC-G ocorreu em um contexto político controverso à condução de ações de cooperação entre o Sul. Em março de 1964, um golpe militar depôs João Goulart da Presidência da República. No campo da política externa, o paradigma americanista, com natureza antes ideológica que pragmática, caracterizou a atuação do Brasil nos primeiros anos do regime. Para o então presidente Castello Branco, o necessário desenvolvimento econômico somente poderia ser alcançado com um mínimo de segurança (PINHEIRO, 2004). Esse viés da segurança nacional foi associado ao decreto de criação do PEC-G. Seu preâmbulo explicita a obrigatoriedade de registro de estudantes estrangeiros beneficiários de convênios culturais (estudantes-convênios). No restante do documento, não são mencionados quaisquer indicativos de cooperação com países em vias de desenvolvimento. O decreto se limita a estabelecer as obrigatoriedades e os compromissos, bastante rígidos, dos participantes do programa:

1. Acatar a indicação do estabelecimento de ensino para o qual fui destinado pelo MEC;

2. Submeter-me ao regulamento do estabelecimento de ensino em que fui matriculado;

3. Apresentar prova, quando pedida, de possuir meios suficientes para me manter no Brasil durante o curso;

4. Não me imiscuir em política interna brasileira;

5. Regressar ao meu país dentro de três meses após a formatura (BRASIL, 1965).

Assim, o decreto que instituiu o PEC-G evidenciou-se como política de controle, editada de modo discricionário, com vistas à identificação ou localização dos estudantes estrangeiros em território nacional. Após o decreto, foram estabelecidos diversos protocolos entre o MRE e o MEC, nos anos: 1967, 1974, 1986, 1987, 1993 e 1998 (BRASIL, 2016d). Se, por um lado, tais protocolos flexibilizaram o programa em relação a determinadas normas (instituindo, por exemplo, a possibilidade de transferência entre cursos e a reprovação em disciplina mais de uma vez), 
por outro estabeleceram critérios restritivos, como: obrigatoriedade de aprovação em exame de língua portuguesa, exclusividade de matrícula em cursos diurnos ou integrais e restrição do tempo de permanência no Brasil após o fim da graduação.

$\mathrm{Na}$ atualização do decreto (BRASIL, 2013), o viés de segurança nacional perdeu força e abriu espaço a normatizaçóes relativas ao papel dos ministérios e das universidades envolvidas, aos pré-requisitos dos candidatos e às obrigatoriedades dos participantes. Apesar das alteraçóes, alguns dispositivos do primeiro decreto ainda são válidos. A participação política, por exemplo, é proibida a qualquer estrangeiro no Brasil pela Lei no 6.815/80 (BRASIL, 1980), promulgada durante a ditadura militar e ainda vigente. Conhecida como "estatuto do estrangeiro", a legislação limita e criminaliza as liberdades civis dos imigrantes e supõe que as migraçôes representam risco à segurança nacional e ao trabalhador brasileiro (REIS, 2004).

A falta de padronização dos dados disponibilizados pelo MRE (BRASIL, 2016d), sobretudo no período de 1964 a 1988, inviabiliza análises documentais aprofundadas dos padróes seguidos nesse intervalo. Em determinados anos, constam informaçóes como país de origem dos participantes e cursos frequentados; em outros, há somente o número de vagas disponibilizadas. A base permite inferir que nesse período foi predominante a participação de estudantes latino-americanos e escassa (inexistente em alguns anos) a presença de estudantes africanos. Também chama atenção a participação dos Estados Unidos, que acompanha a observaçáo de que "o PEC-G possuía características de cooperação que iam além da Cooperação Sul-Sul” (BRASIL, 2016d).

O padrão dos países mais recorrentes ao Brasil nesse domínio se alterou significativamente ao longo da existência do programa. Segundo o MRE (BRASIL, 2016d), 57 países participam do PEC-G atualmente, sendo 25 da África, 25 da Américas do Sul e Central e 7 da Ásia. Os cursos com maior oferta de vagas são: Letras, Comunicação Social, Pedagogia, Administração e Ciências Biológicas. Dados relativos ao período entre 1980 e 1999 não são disponibilizados pelo MRE (BRASIL, 2016d). Entre os anos 2000 e 2015, houve seleção de mais de 6 mil estudantes, sendo a África o continente de origem da maioria deles. Destaca-se a participação dos Palop, sobretudo Cabo Verde (2.933 selecionados), Guiné-Bissau (1.336 selecionados) e Angola (721 selecionados).

De acordo com o Manual do PEC-G (BRASIL, 2016c), cerca de 400 estudantes ingressam em universidades brasileiras anualmente, enquanto 200 se formam. O aumento na participação dos países africanos entre 2010 e 2015 se converge às prioridades da política externa do período. Além da retomada e do estreitamento da relaçáo com o continente, a PEB também se caracterizou pela aproximação com outras potências emergentes, o que talvez justifique o ingresso da África do Sul no PEC-G em 2010, ainda que até o momento o país não tenha enviado estudantes (BRASIL, 2016c). 
O MRE (BRASIL, 2016d) e o MEC (BRASIL, 2016b) não comunicam a quantidade de selecionados que efetivamente concluíram seus estudos nos mais de 50 anos de existência do programa. Somente a partir de 2012, com a implantação do Sistema Integrado de Monitoramento, Execução e Controle no MEC, as universidades puderam registrar todos os dados em uma base comum. A pesquisa de Amaral (2013) informa que até 2013 foram emitidos 2.842 diplomas a estudantes africanos. Ainda sobre o quantitativo de estudantes PEC-G, um aspecto importante é que uma parcela significativa das vagas disponibilizadas não é preenchida. O estudo realizado por Amaral e Meneguel (2015) constata que as universidades oferecem cerca de 3 mil vagas anualmente, ao passo que 700 candidatos se inscrevem, dentre os quais 300 a 400 são selecionados.

Relativamente aos critérios para o ingresso no PEC-G, o candidato deve: ter mais de 18 anos e preferencialmente até 23 anos; ter concluído ou estar cursando o último ano correspondente ao Ensino Médio brasileiro; e apresentar-se à embaixada ou ao consulado brasileiro de seu país para realizar sua inscrição, que é gratuita. É função do participante informar-se sobre as instituições participantes e os cursos disponíveis, sendo que ele pode indicar dois cursos e duas cidades preferenciais (BRASIL, 2013; 2016c).

A documentação necessária para participar da seleção consta de: certificado de conclusão e histórico do Ensino Médio (com média global final igual ou superior a 60\%); certificado ou comprovante de inscrição da Proficiência em Língua Portuguesa para Estrangeiros (Celpe-Bras); certidáo de nascimento do candidato e de seus pais; atestado de saúde física e mental; e termo de compromisso de inscrição e termo de responsabilidade financeira, acompanhado de comprovante de renda que ateste capacidade do signatário (responsável financeiro) de lhe remeter 400 dólares norte-americanos mensalmente. Este termo tem o objetivo de garantir que o estudante contará com fonte financeira que custeie sua viagem ao Brasil, sua instalação e manutenção durante o curso e o seu retorno ao país de origem (BRASIL, 2016d).

É importante perceber que o visto temporário IV, concedido aos estudantes PEC-G, não admite vínculo empregatício ou exercício de quaisquer atividades remuneradas. É permitida somente a participação em estágio curricular e em atividades de pesquisa ou extensão, obedecida a legislação dos estrangeiros residentes temporários. Contudo, segundo Amaral (2013), apesar da obrigatoriedade do termo de responsabilidade financeira, em muitos casos o estudante PEC-G não consegue se manter no país, devido tanto ao alto custo de vida nas capitais, quanto ao fato de que o compromisso financeiro pode não ser cumprido na prática.

O grupo de trabalho sobre a vida acadêmica do aluno PEC-G, conduzido em 2014, evidenciou que esses estudantes enfrentam problemas relacionados à moradia e alimentação; a recursos financeiros para manutenção; ao exame de proficiência em língua portuguesa; ao isolamento e à integração social; e à preparação 
prévia e ao acolhimento (BRASIL, 2016a). Pesquisas stricto sensu sobre o PEC-G e seus participantes ratificam tais evidências, ao realçarem, principalmente, os problemas de não pertencimento, exclusão, preconceito, discriminação racial, moradia e custo de vida (CÓ, 2011; BIZON, 2013; BATISTA, 2015; CABRAL, 2015).

Em determinados casos, os participantes podem solicitar bolsa de estudos do governo brasileiro, no valor de $\mathrm{R} \$ 622,00$, pelo período de um semestre, com possibilidade de renovação. São três as modalidades de bolsas, não acumuláveis, disponibilizadas pelo MRE: Bolsa Mérito, "concedida a estudantes-convênio que apresentarem notável rendimento acadêmico após o primeiro ano de graduação"; Bolsa MRE, "concedida a estudantes-convênio de IES não federais que apresentem debilitada situação financeira após o primeiro ano de graduação no Brasil"; e Bolsa Emergencial, "concedida em caráter extraordinário, nos casos em que o estudante se veja em situação de extrema dificuldade financeira de ordem imprevista". Também existe a possibilidade de que o MRE viabilize ao bolsista mérito a passagem aérea de retorno ao país de origem (BRASIL, 2016c). O MEC, por sua vez, oferece bolsas aos estudantes PEC-G das universidades federais por meio do Projeto Milton Santos de Acesso ao Ensino Superior (BRASIL, 2016a).

De acordo com o MEC (BRASIL, 2016b), a pré-seleção de candidatos é feita pelas missóes diplomáticas brasileiras nos países parceiros, que encaminham a relação dos candidatos e os documentos de inscrição, autenticados por um agente, ao MRE. A seleção final, por sua vez, é feita inteiramente no Brasil. Segundo Amaral e Meneghel (2015, p. 95), o papel das missóes é "receber a inscrição dos estudantes e enviar as informaçôes ao Itamaraty, no Brasil" e "a orientação é para que os funcionários não interfiram no processo em momento algum". Participam da seleção final a Divisão de Temas Educacionais do MRE e a Coordenaçáo-Geral de Relaçôes Estudantis da Secretaria de Educação Superior do MEC, assessoradas por uma comissão. Os resultados são divulgados pelas missóes diplomáticas brasileiras nos países participantes.

Embora sejam responsáveis somente pela pré-seleção, as representações brasileiras nos países parceiros desempenham um papel importante. Os apontamentos feitos por Amaral e Meneghel (2015) em relação à difusão do PEC-G parecem relevantes para justificar o modesto número de inscriçóes efetivadas em relação à quantidade de vagas disponíveis. As autoras constatam que uma ampla divulgaçáo da oportunidade depende do interesse e das condiçôes operacionais das missooes brasileiras em cada país. Ainda que as informaçóes do programa constem na internet, o acesso é reduzido tanto pela falta de centralização, quanto pelo limitado acesso à internet em muitos dos países africanos parceiros, o que torna as possibilidades desiguais. A pesquisa constata, também, a recorrência de problemas com falsificaçâo de documentos por parte dos candidatos.

Quanto aos critérios para a seleção, Amaral e Meneghel (2015) informam que a comissão responsável, que se reúne em Brasília anualmente, considera sobretudo a compatibilidade entre a área de estudo pretendida e as notas obtidas pelos 
participantes nas disciplinas relacionadas à área durante o Ensino Médio. Assim, a avaliação do histórico escolar constitui-se como o principal critério de análise.

Outro aspecto significativo é que o diploma, o histórico escolar e as ementas somente podem ser recebidos pelo estudante na embaixada ou no consulado do seu país de origem (BRASIL, 2013). Isso acontece para que ele cumpra o compromisso de retorno após o término dos estudos. Duas consideraçôes podem ser feitas em relação a essa norma. A primeira, objetiva, diz respeito ao fato de que, dessa maneira, o PEC-G contribui com a contenção da fuga dos cérebros, absorção da mão de obra qualificada dos países menos desenvolvidos, decorrente principalmente da mobilidade acadêmica internacional (KNIGHT, 2012). A segunda, subjetiva, se dá sob a ótica do participante do programa, em termos de falta de liberdade de escolha.

Cabe também discutir o papel das universidades na condução do PEC-G. A disponibilidade de vagas ocorre mediante manifestação de interesse de cada instituição. O MRE (BRASIL, 2016d) informa que 110 instituiçóes federais, estaduais, municipais e privadas, situadas em todos os estados, exceto Rondônia, participam do programa. A maioria dessas universidades encontra-se nos Estados de São Paulo (18), Minas Gerais (15) e Rio Grande do Sul (13). Informaçōes como quantidade de vagas disponibilizadas e ocupadas e cursos disponíveis em cada uma não são mencionadas. Segundo o decreto (BRASIL, 2013), "os ministérios [...] não interferirão em questóes de natureza acadêmica, de atribuição exclusiva das Instituiçóes de Ensino Superior integrantes do programa”. De qualquer modo, questiona-se como são resolvidas as divergências entre as políticas de cada universidade e as políticas do PEC-G, frente à concomitante autonomia administrativa dessas instituiçóes e ao fato de que as normas do PEC-G estão bem estabelecidas no decreto. Amaral e Meneghel (2015) realçam que a atuação das universidades poderia ser mais significativa na gestão do programa, especialmente na seleção dos candidatos, pois são elas que os acompanham em sua jornada acadêmica.

Pensando em termos de reciprocidade, é possível, ainda, fazer um paralelo entre a presença de estudantes de países do Sul nas universidades brasileiras e os processos de internacionalização almejados por essas instituiçóes e pelo governo do país. Até a recente adesão de cotas para negros, estudantes PEC-G africanos eram os maiores representantes da etnia nos campi. Questiona-se, portanto, se as universidades brasileiras têm enxergado esses indivíduos como promotores de diversificação e interculturalidade do ambiente acadêmico, elementos imprescindíveis à internacionalização em casa (LEAL; MORAES, 2016).

\section{Perspectivas do PEC-G como um Programa de Cooperação Sul-Sul}

O questionamento "em que medida as estratégias brasileiras de cooperação Sul-Sul se constituem numa real alternativa ao desenvolvimento?” (MILANI et al., 
2016, p. 17) parece relevante à presente análise do PEC-G. Ao longo de seus mais de 50 anos de existência, o PEC-G, iniciado como política de controle, progrediu consideravelmente. Reduzi-lo a uma abordagem meramente assistencialista não seria adequado, se considerada a oportunidade de formação em nível superior oferecida a milhares de indivíduos de países do Sul.

No entanto, algumas das características do programa parecem distanciá-lo da narrativa oficial brasileira enfatizada para a CSS. No campo da cooperação técnica para o desenvolvimento, os receptores estão dispostos a aprender com as experiências de países com desafios semelhantes para desenvolver programas próprios, condizentes ao seu próprio contexto e às suas reais necessidades. O que o PEC-G tem ensinado a outros países? Uma perspectiva abrangente de cooperação para o desenvolvimento poderia considerar, por exemplo, além da oferta de vagas em universidades brasileiras, iniciativas voltadas ao fortalecimento da educação superior nacional dos países envolvidos. Um olhar voltado à reciprocidade e à igualdade entre as partes, por sua vez, deveria considerar que o Brasil também pode aprender com seus parceiros.

Ademais, o PEC-G se revela como um programa demasiadamente restritivo e seletivo, pelo excesso de condicionalidades impostas no regulamento do programa. Além disso, alguns aspectos mais amplos, como o tratamento do estrangeiro no Brasil, suscitam debates sobre a configuração do PEC-G como uma modalidade de CSS. Nesses termos, a reflexão de Leite (2012, p. 34) parece relevante:

Em última instância, classificar determinada relação Sul-Sul como cooperativa é uma questão empírica, que não pode ser analisada levando-se em conta apenas trocas específicas de conhecimento entre os atores envolvidos em iniciativas de cooperação técnica, as quais muitas vezes não se concretizam.

Cabe realçar a ausência de diálogo direto entre o Brasil e os ministérios da Educação dos países parceiros no que se refere ao PEC-G. Quando necessária, a comunicação ocorre somente por meio do consulado ou da embaixada brasileira (AMARAL; MENEGHEL, 2015). A CSS pressupóe o envolvimento das partes em condiçôes de igualdade e reciprocidade e implica participação ativa do receptor. No caso do PEC-G, há inexistência (ao menos oficial) da participação de atores dos países receptores, que conhecem melhor suas condiçóes e suas demandas de desenvolvimento. Inclusive, tais demandas não condizem necessariamente com a noção de desenvolvimento imposta pelo mundo ocidental.

Ao que parece, é o Brasil que estabelece a totalidade da agenda do PEC-G na mesma linha do que ocorre na ajuda Norte-Sul. Não se sabe, por exemplo, se os cursos ofertados condizem às necessidades dos 57 países participantes. Da mesma forma, não se tem informaçóes acerca dos resultados obtidos com o programa, de modo que parecem necessários mecanismos de monitoramento e avaliação. Amaral e Meneghel (2015, p. 102) reforçam que "mesmo com o modelo de não indicação por 
parte dos países, aparentemente existe algum tipo de benefício àqueles estudantes das elites nacionais africanas".

Uma analogia com o estudo de Haas (2007) sobre a relação entre migração e desenvolvimento parece oportuna. $\mathrm{O}$ autor entende como equivocada a noção popular de que os mais pobres têm a maior tendência de migrar. A migração é um processo seletivo: a fim de migrar, as pessoas precisam, além de recursos humanos, financeiros e sociais, de aspiraçóes para fazê-lo. Assim, é possível que as restrições impostas pelo PEC-G e as falhas na difusão do programa excluam indivíduos para os quais a oportunidade realmente significaria implicaria desenvolvimento. Sen (2000) concebe o desenvolvimento em uma perspectiva abrangente, ao equipará-lo ao processo de expansão das verdadeiras liberdades. $\mathrm{O}$ conceito deve ser medido levando-se em conta a capacidade das pessoas em controlar suas vidas. Se a CSS procura distanciar-se do mainstream praticado pelos países centrais, é relevante que um conceito mais abrangente para o desenvolvimento embase o estabelecimento de políticas voltadas a esse fim.

Compreender o PEC-G sob a ótica da CSS requer considerar os padróes brasileiros de condução da política externa. A despeito da ênfase dada pelo Brasil a uma CSS pautada na solidariedade, o país sempre defendeu tratamento diferenciado nos fóruns multilaterais. A ênfase do discurso na busca pela simetria com países do Sul, dessa forma, não pode ser aceita acriticamente. Como Visentini (2010) argumenta, o Brasil enxerga as potencialidades da África não somente do ponto de vista econômico, mas também político. Assim, seus objetivos no continente são de médio e longo prazo.

A teoria social demonstra que a cooperação é um fenômeno complexo, que engloba recompensas de várias naturezas (LEITE, 2012). Uma questão adicional que se levanta é: quais recompensas indiretas o Brasil tem almejado alcançar com o PEC-G? Schardong (2012) considera que, ao voltarem aos seus países, os ex-alunos PEC-G estarão mais receptivos à política externa do Brasil, da mesma forma que disseminarão aspectos culturais brasileiros.

\section{Considerações finais}

O propósito deste artigo foi analisar o PEC-G na ótica da CSS brasileira. Para tanto, realizou-se um levantamento bibliográfico e documental. Enquadrou-se o PEC-G contextual e paradigmaticamente, por meio de um diálogo entre suas principais características, os padróes históricos da política externa e a cooperação horizontal contemporânea.

Concluiu-se que, a despeito da nítida ascensão do PEC-G em um sentido cooperativo, o excesso de condicionalidades impostas e a exclusividade do governo brasileiro no estabelecimento da agenda tornam o programa 
demasiadamente restritivo e seletivo, o que o distancia da sua configuraçáo como modalidade de CSS, pelo menos como enfatizada no discurso oficial. Questiona-se, portanto, até que ponto o PEC-G contribui para o desenvolvimento a que se propóe.

A PEB, como política pública, promove articulaçóes e arranjos institucionais-burocráticos internos, ao mesmo tempo em que suscita demandas e conflitos de grupos domésticos distintos (SALOMÓN; PINHEIRO, 2013). A história demonstra que a aproximação do Brasil com outros países do Sul ocorreu nos momentos em que tal proximidade era oportuna, segundo uma conjugação dinâmica dos interesses e das percepçóes de seus representantes. Apesar da tradicional existência do PEC-G, não existem garantias de sustentabilidade. O contexto dos anos 2000 se demonstrou como favorável a ações de CSS no Brasil, que era representado por um governo de esquerda, em um período de relativo crescimento econômico.

Questóes contemporâneas, como a crise econômica mundial e a instabilidade política e econômica do Brasil, conduzem a hipóteses sobre as condiçôes que o país terá para manter sua capacidade de oferecer projetos de cooperação. Se o PEC-G pretende representar um legado positivo em relação ao desenvolvimento do Sul, é relevante que incorpore uma perspectiva sustentável, no sentido de contribuir para que, a partir da experiência brasileira, os parceiros desenvolvam programas próprios, condizentes ao seu contexto e às suas demandas. Se compreendida como um processo complexo de trocas, a CSS deve distanciar-se de abordagens reducionistas que levam à formação de um pensamento meramente normativo (LEITE, 2012). São necessários, portanto, estudos empíricos que permitam mensurar os resultados alcançados com essa modalidade de cooperação e incidir luz sobre as perspectivas futuras do PEC-G.

\section{Notas}

1. O Sul é compreendido aqui "não como uma categoria geográfica, mas como o agrupamento que reúne os chamados 'países em desenvolvimento' (países de renda média e países de renda baixa)” (LEITE, 2012, p. 4). Para Santos e Meneses (2010), o Sul é um campo de desafios epistêmicos, que procura reparar os danos e os impactos historicamente causados pelo capitalismo em sua relação colonial com o mundo.

2. Discurso do então presidente da República, Luís Inácio Lula da Silva, em visita a Moçambique, em 2008.

3. "Alternativa usada por países com poucos recursos para ampliar sua presença nas relaçóes internacionais” (FLEMES; SARAIVA, 2014, p. 214). 


\section{Referências}

AMARAL, J. Atravessando o atlântico: o Programa Estudante Convênio de Graduação e a cooperação educacional brasileira. Dissertação (Mestrado) - Universidade de Brasília, Brasília, 2013.

AMARAL, J.; MENEGHEL, S. Programa Estudante Convênio de Graduação: apontamentos sobre processos e papel das universidades. In: PEREIRA, E.; HEINZLE, M. (Eds.). Internacionalização na educação superior: políticas, integração e mobilidade acadêmica. Blumenau: Edifurb, 2015.

BATISTA, I. S. O Projeto Milton Santos de Acesso ao Ensino Superior como politica de assistência estudantil ao Programa de Estudantes-Convênio de Graduação. Dissertação (Mestrado) - Universidade de Brasília, Brasília, 2015.

BIZON, A.C.C. Narrando o exame Celpe-Bras e o Convênio PEC-G: a construção de territorialidades em tempos de internacionalização. Tese (Doutorado) - Universidade Estadual de Campinas, Campinas, 2013.

BRASIL. Decreto no 55.613, de 20 de janeiro de 1965. 1965. Disponível em: <http://www.planalto.gov.br/ccivil 03/decreto/1950-1969/D55613.htm >. Acesso em: 23 set 2016.

Lei $n^{o}$ 6.815, de 19 de agosto de 1980. 1980. Disponível em: <http://www. planalto.gov.br/ccivil_03/LEIS/L6815.htm>. Acesso em: 23 set 2016.

. Decreto $n^{\circ}$ 7.948, de 12 de março de 2013. 2013. Disponível em: $\leq$ http:// www.planalto.gov.br/ccivil_03/_Ato2011-2014/2013/Decreto/D7948.htm>. Acesso em: 23 set 2016.

. Ministério da Educação. PEC-G: comemoração dos 50 anos do programa. Brasília: MEC, 2016a.

Ministério da Educação. Programa Estudante-convênio de Graduação. 2016 b. Disponível em: $\leq$ http://portal.mec.gov.br/pec-g $>$. Acesso em: 23 set 2016.

- Ministério das Relaçôes Exteriores. Manual do Estudante-Convênio. Brasília: Ministério das Relaçôes Exteriores, 2016c.

Ministério das Relaçôes Exteriores. Programa de Estudantes-Convênio de Graduação. 2016d. Disponível em: <http://www.dce.mre.gov.br/PEC/PECG.php $>$. Acesso em: 23 set 2016.

CABRAL, F.M.T. Os estudantes africanos nas Instituiçôes de Ensino Superior brasileiras: o Programa de Estudante Convênio de Graduação (PEC-G). Dissertação (Mestrado) Universidade Federal do Rio Grande do Sul, Porto Alegre, 2015.

CÓ, J.P.P. Filhos da independência: etnografando os estudantes Bissau-Guineenses do PEC-G em Fortaleza-CE e Natal-RN. Dissertação (Mestrado) - Universidade Federal do Rio Grande do Norte, Natal, 2011. 
CHISHOLM, L. Introduction: rethoric, realities, and reasons. In: CHISHOLM, L.; STEINER-KHAMSI, G. South-south cooperation in Education and Development. África do Sul: HSRC Press, 2009.

DEGNBOL-MARTINUSSEM, J.; ENGBERG-PEDERSON, P. Aid: understanding International Development Cooperation. Londres/Nova York: Zed Books, 2003.

ENGSTROM, P. Brazilian foreign policy and human rights: change and continuity under Dilma. Critical Sociology, v. 38, n. 6, p. 835-849, 2012.

FLEMES, D.; SARAIVA, M.G. Potências emergentes na ordem de redes: o caso do Brasil. Revista Brasileira de Politica Internacional, v. 57, n. 2, p. 214-232, 2014.

HAAS, H. de. Turning the tide? why development will not stop migration. Development and Change, v. 38, n. 5, 2007.

KNIGHT, J. Student mobility and internationalization: trends and tribulations. Research in Comparative and International Education, v. 7, n. 1, p. 20-33, 2012.

LANCASTER, C. Foreign aid: diplomacy, development, domestic politics. Chicago/ Londres: The University of Chicago Press, 2007.

LEAL, F.G.; MORAES, M.C.B. Internacionalização do currículo: um olhar crítico fundamentado no pensamento complexo. In: LUNA, M. (Ed.). Internacionalizaçáo do curriculo: educação, interculturalidade e cidadania global. Curitiba: Pontes, 2016.

LEITE, I.C. Cooperação sul-sul: conceito, história e marcos interpretativos. Observatório político sul-americano, v. 7, n. 3, 2012.

MAWDSLEY, E. From recipients to donors: emerging powers and the changing development landscape. Londres/Nova York: Zed Books, 2012.

MILANI, C.; CONCEIÇÃO, F.; M'BUNDE, T. Cooperação sul-sul em Educação e Relaçôes Brasil-Palop. Caderno CRH, v. 29, p. 13-32, jan./abr. 2016.

MILANI, C.R.S.; MUÑOZ, E.E.; DUARTE, R.S.; KLEIN, M. Atlas da politica externa brasileira. Rio de Janeiro: Editora da UERJ, 2015.

MORGENTHAU, H. A political theory of foreign aid. The American Political Science Review, v. 56, n. 2, p. 301-309, 1962.

OGWU, J.U.A. La cooperación Sur-Sur: problemas, posibilidades y perspectivas en una relación emergente. Nueva Sociedad, n. 60, p. 557-558, 1982.

PINHEIRO, L. Política Externa Brasileira. Rio de Janeiro: Zahar, 2004.

Traídos pelo desejo: um ensaio sobre a teoria e a prática da Política Externa Brasileira contemporânea. Contexto Internacional, v. 22, n. 2, 2000.

REIS, R.R. Soberania, direitos humanos e migraçóes internacionais. Revista Brasileira de Ciências Sociais, v. 19, n. 55, 2004.

SALOMÓN, M.; PINHEIRO, L. Análise de política externa e política externa brasileira: trajetória, desafios e possibilidades de um campo de estudos. Revista Brasileira de Politica Internacional, v. 56, n. 1, p. 40-59, 2013. 
SANTOS, B. de S.; MENESES, M. P. Epistemologias do Sul. São Paulo: Cortez, 2010.

SCHARDONG, M.M. Cooperação e globalização: o programa Estudante-convênio - Graduação na Política Externa Brasileira do Século 21. Monografia (Graduação) - Universidade de Brasília, Brasília, 2012.

SEN, A. Development as freedom. Nova York: Alfred A. Knopf, 2000.

SOARES DE LIMA, M.R. Ejes analíticos y conflicto de paradigmas en la política exterior brasilena. América Latina/Internacional, v. 1, n. 2, 1994.

SOUZA, A.M. Repensando a cooperação internacional para o desenvolvimento. Brasília: IPEA, 2014.

STEINER-KHAMSI, G. A way out from dependency trap in educational development? In: CHISHOLM, L.; STEINER-KHAMSI, G. South-south cooperation in Education and Development. South Africa: HSRC Press, 2009. p. 241-259.

VALENÇA, M.M.; CARVALHO, G. Soft power, hard aspirations: the shifting role of power in Brazilian foreign policy. Brazilian Policital Science Review, v. 8, p. 66-94, 2014.

VIGEVANI, T.; CEPALUNI, G. A Política Externa de Lula da Silva: a estratégia da autonomia pela diversificação. Contexto Internacional, v. 29, n. 2, p. 273-335, 2007.

VISENTINI, P.F. O Brasil e o Mundo: a política externa e suas fases. Ensaios FEE, v. 20, n. 1, p. 134-154, 1999.

. South-south cooperation, prestige diplomacy or "soft imperialism"? Lula's government Brazil-Africa relations. Século XXI, v. 1, n. 1, p. 65-84, 2010.

Recebido em 4 de janeiro de 2017.

Aceito em 18 de julho de 2017. 